\title{
El agravio comparativo económico de las personas con discapacidad de la ciudad de Barcelona
}

\section{Economic comparative grievance of people with disabilites in the city of Barcelona}

\section{Resumen}

En este artículo se aproxima el agravio comparativo económico de las personas con discapacidad de la ciudad de Barcelona estableciendo una categorización previa de trece perfiles distintos de discapacidad. Además, se distinguen dos grupos de edad: de 6 a 64 años y el colectivo de 65 años o mayores. Los datos se circunscriben al año 2017. Se realiza una simulación de costes (distinguiendo entre costes directos e indirectos) y de ingresos, ayudas y bonificaciones en base al método de estándares presupuestarios consensuados. El trabajo finaliza con una propuesta de tarifación que contempla tanto el perfil de discapacidad como el agravio comparativo económico soportado.

\section{Palabras clave}

Discapacidad, agravio comparativo económico, tarifación pública, costes y beneficios.

\footnotetext{
Abstract

This article approaches the economic comparative grievance of people with disabilities in the city of Barcelona, establishing a prior categorization of thirteen different disability profiles. In addition, two age groups are distinguished: from 6 to 64 years old and the group 65 years or older. The data is limited to the year 2017. A simulation of costs (distinguishing between direct and indirect costs) and of income, aid and bonuses is carried out following the consensual budget standards approach. The work ends with a pricing proposal that includes both the disability profile and the suffered economic comparative grievance.
}

\section{Keywords}

Disability, economic comparative grievance, public pricing, costs and benefits.

\author{
Jordi Puig i Gabau \\ $<$ jordi.puig@esci.upf.edu>
}

Escola Superior de Comerç Internacional (ESCI-UPF). España

\section{Marta Segura Bonet}

<marta.segura@esci.upf.edu>

Escola Superior de Comerç Internacional (ESCI-UPF). España

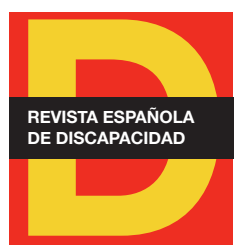

\section{Para citar:}

Puig, J. y Segura, M. (2021). El agravio comparativo económico de las personas con discapacidad de la ciudad de Barcelona. Revista Española de Discapacidad, 9(1), pp. 153-178.

Doi: <https://doi.org/10.5569/23405104.09.01.08>

Fecha de recepción: 08-10-2020 Fecha de aceptación: 06-04-2021 


\section{Introducción ${ }^{1}$}

El agravio comparativo económico de las personas con discapacidad es el coste adicional que comporta vivir con una discapacidad en igualdad de condiciones que las personas del entorno.

Antares Consulting (2006), a través del Ayuntamiento de Barcelona y del Instituto Municipal de Personas con Discapacidad (IMPD), publicó el primer estudio en España sobre el agravio comparativo económico de las personas con discapacidad: El greuge comparatiu econòmic de les persones amb discapacitat de la ciutat de Barcelona. El sobreesforç econòmic que origina la discapacitat. En 2019 se llevó a cabo un nuevo estudio que tenía como objetivo actualizar y ampliar los contenidos del anterior a los datos y a la realidad de las personas con discapacidad del año 2017, ampliando los grupos de edad contemplados e incorporando nuevos tipos de gastos e ingresos. Este artículo es un resumen del amplio análisis realizado.

El objetivo de la investigación es cuantificar el sobresfuerzo económico que asumen las personas con discapacidad y sus familias para mantener los estándares de vida de su entorno inmediato, identificando las necesidades de apoyo de cada perfil de discapacidad y también las diferentes ayudas, bonificaciones e ingresos derivados de su situación personal. Adicionalmente, los resultados obtenidos resultan de interés en el diseño de políticas públicas, proponiéndose criterios de tarifación en el acceso a bienes y servicios públicos que incorporan el agravio comparativo económico realmente soportado por las personas con discapacidad.

\section{Metodología}

Desde una perspectiva económica, las diferentes situaciones de discapacidad inciden en las personas y en los hogares, en los que residen en tres aspectos: 1) asunción de un sobrecoste vinculado a la adquisición (o mayor uso) de un conjunto de bienes y de servicios que permitan atender aquellas necesidades encaminadas a facilitar el desarrollo de la actividad diaria y la integración de la persona con discapacidad; 2) reducción de alternativas en los diferentes ámbitos de la vida, tanto para las personas con discapacidad como para las de su entorno, en forma de costes de oportunidad; y 3) consecución de un nivel de ingresos menor.

En correspondencia, cabe valorar el agravio comparativo económico tanto desde la perspectiva de los costes (sistemáticamente más elevados) como de los ingresos presentes y futuros, que se presuponen inferiores.

\footnotetext{
1. La investigación de base que ha dado pie al presente artículo se ha desarrollado gracias a la colaboración del Instituto Municipal de Personas con Discapacidad (IMPD), ESCI-UPF, el Parque Sanitario Sant Joan de Déu, COCARMI, DINCAT, la Federación de Salud Mental Cataluña, ECOM y ONCE. Comisión impulsora: Meritxell Caralt, secretaria técnica de COCARMI; Alba Mestres, técnica de Planificación y Evaluación del IMPD; Sergi Morera, jefe de Planificación y Evaluación del IMPD; Laura Trujillo, técnica de Planificación y Evaluación del IMPD. Equipo de investigación: Jordi Puig, profesor asociado de ESCI-UPF; Marta Segura, jefa de estudios del Grado en Negocios y Marketing Internacionales (GNMI) de ESCI-UPF. Colaboración: Sílvia Ángel, psicóloga coordinadora del Parque Sanitario Sant Joan de Déu; María Luisa de la Puente, jefa de Calidad y Seguridad del Parque Sanitario Sant Joan de Déu. El documento de trabajo completo puede solicitarse por correo electrónico a redis@cedd.net, o consultarse en https://bcnroc.ajuntament.barcelona.cat/jspui/handle/11703/116073.
} 
En la literatura, los diferentes estudios que han abordado el cálculo del agravio comparativo económico de la discapacidad en estas dos dimensiones (mayores costes y menores ingresos) se han planteado siguiendo tres posibles metodologías o aproximaciones de cálculo².

- El método de los estándares de vida (standard of living approach) parte de la asociación de nivel de vida con nivel de renta y propone la valoración de las privaciones y de la reducción en el estándar de vida de un hogar con una (o más) persona con discapacidad para un determinado nivel de renta o, alternativamente, el cálculo del ingreso adicional que le sería necesario para alcanzar un estándar de vida equivalente ${ }^{3}$. La principal limitación de esta aproximación reside en suponer que ambos hogares requieren adquirir la misma cesta de bienes y de servicios para alcanzar un nivel de vida determinado (Tibble, 2005) sin contemplar las necesidades específicas de diferentes discapacidades o el uso más o menos intensivo de algún bien o servicio ${ }^{4}$.

- Las aproximaciones basadas en el gasto (expenditure based approach) proponen la evaluación de los gastos incurridos y de los ingresos percibidos reales por parte de hogares representativos con situaciones de discapacidad ya sea mediante i) entrevistas directas (direct survey approach), con la posible dificultad de distinguir entre costes regulares y sobrecostes o, en paralelo, la limitación por parte de los entrevistados de conocer los recursos disponibles ${ }^{5}$ o, ii) solicitando el registro directo de los mismos en diferentes rúbricas (expenditure diary approach). Además de las limitaciones anteriores, esta metodología adolece de no captar el efecto sustitución en la adquisición de bienes y servicios asociados a la discapacidad por otros de consumo general, por la propia existencia de restricciones presupuestarias ${ }^{6}$.

- El enfoque de los estándares presupuestarios (budget standard approach) se fundamenta en el desarrollo de un listado detallado del conjunto de costes y de recursos que un hogar requiere para alcanzar un determinado nivel de bienestar. La identificación y valoración de cestas de bienes y de servicios, con elementos comunes y con especificidades de una determinada discapacidad, proporcionará estimaciones promedio del coste o presupuesto específico para los diferentes perfiles de discapacidad que se definan. La validez y potencia de esta metodología se sustenta en que, por un lado, se registren y describan con el máximo detalle y transparencia los gastos e ingresos asociados a una clasificación coherente, tanto del tipo como de la severidad de la discapacidad y, por otro, en que el proceso de validación de los elementos considerados sea preciso y que los supuestos de valoración y de cálculo sean veraces y justificados. Si bien el sistema de cálculo es esencialmente objetivo, por el hecho de fundamentarse en exceso en la percepción de expertos, puede generar aproximaciones del coste con un cierto sesgo al alza. De aquí la importancia de que los diferentes supuestos de cálculo sean contrastados con la comunidad (estándares presupuestarios consensuados - consensual budget standards) ${ }^{7}$.

\footnotetext{
2. Para una exhaustiva revisión y discusión, véase Berthoud (1991), Cullinan et al. (2008) y Wilkinson-Meyers et al. (2010).

3. Véase Antón et al. (2016) para diferentes países de Europa y Antón y Braña (2011) para España.

4. La aproximación para superar esta limitación pasa por el cálculo de escalas de equivalencia, similares a las que permiten la comparación de ingresos entre hogares con diferentes composiciones.

5. Para el Reino Unido, véase Matthews y Truscott (1990).

6. En Indecon (2004) se incluyen estimaciones del coste de la discapacidad con esta aproximación para Irlanda.

7. Partiendo de esta metodología, el Center for Research in Social Policy (CRSP) y la University of York desarrollaron entre 2006-2008 el programa Minimum Income Standard (MIS) para el Reino Unido con el objetivo de construir indicadores consensuados del ingreso necesario para alcanzar un nivel aceptable de vida ante distintas circunstancias. También, Hill et al. (2015) preguntan a grupos de personas con impedimentos visuales y auditivos el listado detallado de ítems necesarios (se precisa la distinción entre necesidades y deseos) para alcanzar un estándar de vida mínimo y construyen una valoración del coste adicional que les representa.
} 
Para el cálculo del agravio comparativo económico de las personas con discapacidad, la metodología que se ha seguido en el presente estudio es la de los estándares presupuestarios consensuados. Se ha procedido a la cuantificación económica en la media del conjunto de recursos (bienes y servicios) que requieren tanto las personas con discapacidad como su entorno y a la identificación del conjunto de ayudas, bonificaciones e ingresos asociados para distintos perfiles de discapacidad. A efectos de evaluación, se ha llevado a cabo una revisión exhaustiva de las distintas tipologías de costes y de ingresos y de sus correspondientes importes recurriendo a información secundaria (bases de datos, estadísticas o publicaciones) y contrastado y validado acudiendo a fuentes de información primaria (especialistas, profesionales, entidades y personas con discapacidad y sus familias).

\section{Revisión bibliográfica}

La prospección de referentes internacionales que abordan el cálculo del agravio comparativo económico de las personas con discapacidad, mayoritariamente concentrados en la esfera anglosajona ${ }^{8}$, pone en evidencia las significativas diferencias en los resultados obtenidos en función de la metodología de cálculo empleada, del país y, especialmente, de la definición y clasificación de las diferentes situaciones de discapacidad. A continuación se presenta una revisión de diferentes aproximaciones metodológicas al cálculo del agravio comparativo económico de las personas con discapacidad ${ }^{9}$.

\section{Referencias empleando el método de los estándares de vida (standard of living approach)}

Para el Reino Unido, Kuklys (2004) incorpora la heterogeneidad como factor determinante, valorando el espacio de capacidades funcionales potenciales de una persona. El estudio estima que una persona adulta con discapacidad necesitaría 1,45 veces el ingreso de un hogar sin discapacidad para alcanzar el mismo nivel de vida. También para el Reino Unido, Zaidi y Burchart (2005) estiman, para el 2002, los costes extra asociados a la discapacidad. Los resultados obtenidos varían en función de características socioeconómicas del hogar y de la severidad de la discapacidad. Morciano y Hancock (2015) aproximan el sobrecoste en la tercera edad de una discapacidad superior a la media.

En Indecon (2004) se ofrecen cálculos y estimaciones del coste de la discapacidad con diferentes aproximaciones metodológicas para Irlanda. Con la aproximación de los estándares de vida se aproxima el coste adicional asociado a una situación de discapacidad con un nivel de renta medio pero sin contemplar correcciones asociadas a la severidad de la discapacidad. Cullinan et al. (2008) modelizan los sobrecostes asociados a la discapacidad en el 2001. Los resultados obtenidos dependen de la severidad de la discapacidad y de la tipología del hogar. Igualmente, en Cullinan et al. (2013), se estima el coste de la discapacidad para población de la tercera edad como porcentaje sobre la renta usando datos de la encuesta Living in Ireland

\footnotetext{
8. Las aproximaciones a la realidad socioeconómica de la discapacidad en países en vías de desarrollo son muy limitadas y se centran en cuestiones de salud y de análisis de poblaciones vulnerables.

9. Para una revisión de la literatura a nivel internacional sobre la aproximación a los costes directos asociados a la discapacidad (en algunos casos, totales y en otros, vinculados a la atención sanitaria), tanto desde aproximaciones cuantitativas como cualitativas y para diferentes subgrupos de población y tipologías de discapacidad, véase Mitra et al. (2017).
} 
$(2001)^{10}$. En Saunders (2007) se ofrecen estimaciones del coste de la discapacidad sobre la renta con esta misma aproximación para Australia.

Para España, Jiménez-Lara y Huete-García (2011) evalúan la diferencia entre el ingreso medio de los hogares en los que viven personas con discapacidad y los hogares sin personas con discapacidad en función del número de miembros y de personas con discapacidad usando microdatos de la Encuesta de discapacidad, autonomía personal y situaciones de dependencia EDAD (2008) - Módulo Hogares (Instituto Nacional de Estadística, 2008a). Antón y Braña (2011) estiman los costes de discapacidades moderadas y severas para los hogares españoles explotando la información contenida en la Encuesta de condiciones de vida 2007 (Instituto Nacional de Estadística, 2008b).

\section{Referencias basadas en el gasto (expenditure based approach)}

En Martin y White (1998) se ofrecen estimaciones subjetivas de costes regulares asociados a la discapacidad a partir de entrevistas directas (direct survey approach) a una muestra aleatoria de personas con discapacidad. Por otro lado, Matthews y Truscott (1990) estiman el coste adicional de la discapacidad a partir de la comparación de algunas rúbricas de gasto en hogares con dos miembros con y sin discapacidad, controlando por la variable renta y explotando la Family Expenditure Survey en base a patrones de consumo.

\section{Referencias empleando el método de los presupuestos estándar (budget standard approach)}

Dobson et al. (2001) aproximan, para menores de edad del Reino Unido, el coste mínimo necesario en discapacidades severas tal que permita obtener una calidad de vida razonable y lo comparan con patrones reales de gasto. También en el Reino Unido, Smith et al. (2004), presentan la evaluación de los costes de la discapacidad a partir del listado y valoración de aquellos bienes y servicios requeridos por las personas con discapacidad a fin de mantener un determinado nivel de vida. Hirsch y Hill (2016), estiman los costes adicionales en los que incurren hogares con personas con discapacidades visuales y auditivas y consideran también los costes asociados a cómo éstas viven su discapacidad.

Para Irlanda, en Indecon (2004) se incluye la valoración de un listado de bienes y servicios compartidos en diferentes discapacidades, complementados con ítems específicos de algunas de ellas.

Wilkinson-Meyers et al. (2010) plantean identificar los recursos requeridos por la población entre 18 y 64 años con cualquier tipo de impedimento, controlando por el entorno socioeconómico e incluyendo costes de oportunidad en Nueva Zelanda. También en Wilkinson-Meyers et al. (2015), usando la misma metodología y validando los resultados a través de focus-groups, ajustan los costes adicionales en equipamiento, modificaciones, transporte, apoyo y tiempo requeridos para personas con dificultades físicas para alcanzar un nivel estándar de vida.

En España, el estudio de Antares Consulting (2006) propone valoraciones y estimaciones del agravio comparativo económico de la discapacidad en la ciudad de Barcelona para trece perfiles de discapacidad. La Confederación Española de Asociaciones a favor de las Personas con Discapacidad Intelectual (en la actualidad, Plena Inclusión) (Feaps, 2009) aproxima el sobreesfuerzo económico para hogares con miembros con discapacidad intelectual como la diferencia entre costes de bienes y servicios y costes de oportunidad y ayudas, subvenciones y exenciones.

10. Más información: https://www.ucd.ie/issda/data/livinginirelandlii/. 


\section{Cálculo del agravio comparativo económico}

\subsection{Perfiles vinculados al tipo de discapacidad según la necesidad de apoyo}

El presente estudio mantiene los trece perfiles de discapacidad identificados en el estudio original. Tal decisión ha contado con el aval de los expertos médicos y asistenciales que han participado en el proyecto de investigación. A continuación, se definen brevemente los perfiles considerados ${ }^{11}$.

Las personas con discapacidad física se han agrupado en tres perfiles según las necesidades de apoyo requeridas:

- Personas con discapacidad física del grupo 1 (DF1): dificultades para desplazarse pero con las habilidades manipulativas y comunicativas intactas. Son autónomas para la mayoría de las actividades de la vida diaria y necesitan ayuda con carácter puntual.

- Personas con discapacidad física del grupo 2 (DF2): dificultades para desplazarse y, en cierto grado, ven mermadas sus capacidades de manipulación. También pueden tener afectadas las capacidades comunicativas. Necesitan ayuda para la mayoría de las actividades de la vida diaria.

- Personas con discapacidad física del grupo 3 (DF3): dificultades para desplazarse, manipular y, algunas, para comunicarse. Además, se incluyen las personas con graves problemas de comunicación, tengan o no el desplazamiento y la manipulación afectados. Requieren apoyo personal de manera continuada para las actividades de la vida diaria, transferencias y otras actividades de la vida.

Las personas con discapacidad intelectual se han separado en tres grupos en función de la intensidad de apoyo requerida:

- Personas con discapacidad intelectual del grupo 1 (DI1): discapacidad intelectual leve, autónomas para hacer la mayoría de actividades de la vida diaria, pero que necesitan supervisión y ayuda para tomar ciertas decisiones.

- Personas con discapacidad intelectual del grupo 2 (DI2): discapacidad intelectual media, que requieren ayuda para la mayoría de las actividades de la vida diaria y también para desarrollar otras actividades. Necesitan acompañamiento para tener autonomía.

- Personas con discapacidad intelectual del grupo 3 (DI3): discapacidad intelectual grave, que requieren apoyo constante para la realización de las actividades de la vida diaria y para hacer otras actividades. Necesitan una tutela permanente y ayuda personal constante.

Los perfiles de personas con trastornos mentales son los siguientes:

- Personas con trastornos mentales del grupo 1 (TM1) que pueden conseguir estabilidad con un tratamiento adecuado. Son autónomas para realizar la mayoría de actividades de la vida diaria y solo requieren supervisión periódica.

11. En ulteriores actualizaciones del presente estudio sería conveniente modificar los perfiles de discapacidad considerados, con el objeto de incorporar las recomendaciones del sector (a modo de ejemplo, evaluando separadamente el perfil de personas sordociegas). 
- Personas con trastornos mentales del grupo 2 (TM2) que, a pesar de seguir el tratamiento propuesto, requieren un control continuado y ayuda para desarrollar diversas actividades de la vida diaria.

- Personas con trastornos mentales del grupo 3 (TM3), cuyo estado es grave a pesar del seguimiento médico. Necesitan asistencia personal continuada y apoyo para la realización de las actividades de la vida diaria.

Las discapacidades sensoriales se han subdividido en dos grupos: visual y auditivo.

- Personas con resto visual (DV1): tienen una grave discapacidad visual y conservan o bien la agudeza visual para hacer actividades, o bien el campo visual, lo que les permite desplazarse sin bastón ni perro guía, con productos de apoyo u ópticas. Son autónomas y no necesitan ayuda para realizar las actividades de la vida diaria.

- Personas con ceguera (DV2): necesitan productos de apoyo para mejorar su calidad de vida y también necesitan apoyo puntual, sobre todo en desplazamientos o para desarrollar ciertas actividades de la vida diaria.

Las personas con discapacidad auditiva se han clasificado a partir de la lengua escogida para comunicarse, pues dicha elección comporta la necesidad de diferentes tipos de apoyo:

- Personas que utilizan lengua oral (DA1) con hipoacusia de diferentes grados que optan por comunicarse mediante la lengua oral, con productos de apoyo o lectura labial. Son autónomas, pero necesitan ayuda especializada (logopedia, transcripción, subtitulación, etc.).

- Personas que utilizan lengua de signos (DA2) con hipoacusia de diferentes grados que optan por comunicarse mediante la lengua de signos. Son autónomas, pero requieren productos de apoyo, interpretación de lengua de signos, etc.

Para cada uno de los trece perfiles vinculados a las distintas tipologías de discapacidad se ha calculado la media de costes asumidos y el valor medio de los ingresos y de las ayudas percibidas.

\subsection{Estimación de los costes}

Tras la concreción de las distintas partidas de coste, se ha procedido a su evaluación aplicando la metodología de los estándares presupuestarios consensuados. Las valoraciones se han realizado en base al cálculo de promedios, es decir, considerando estimaciones de gasto a partir de medidas de tendencia central (media o mediana) y contemplando dos tipologías:

- Los costes directos evalúan los gastos económicos en atención personal, los servicios y los elementos de apoyo que debe afrontar la persona con discapacidad y se derivan de manera directa de su situación de discapacidad. Son costes directamente percibidos por la persona con discapacidad y su entorno inmediato y deben sufragarse de manera habitual o recurrente.

- Los costes indirectos aproximan el valor económico de lo que la persona con discapacidad o su entorno dejan de percibir como consecuencia de la situación de discapacidad. Son costes vinculados a las oportunidades perdidas (en materia de formación, empleo, ocio, bienestar) tanto por la persona con discapacidad como por parte del cuidador principal, derivadas de la situación de discapacidad. 
Figura 1. Categorías de costes analizadas
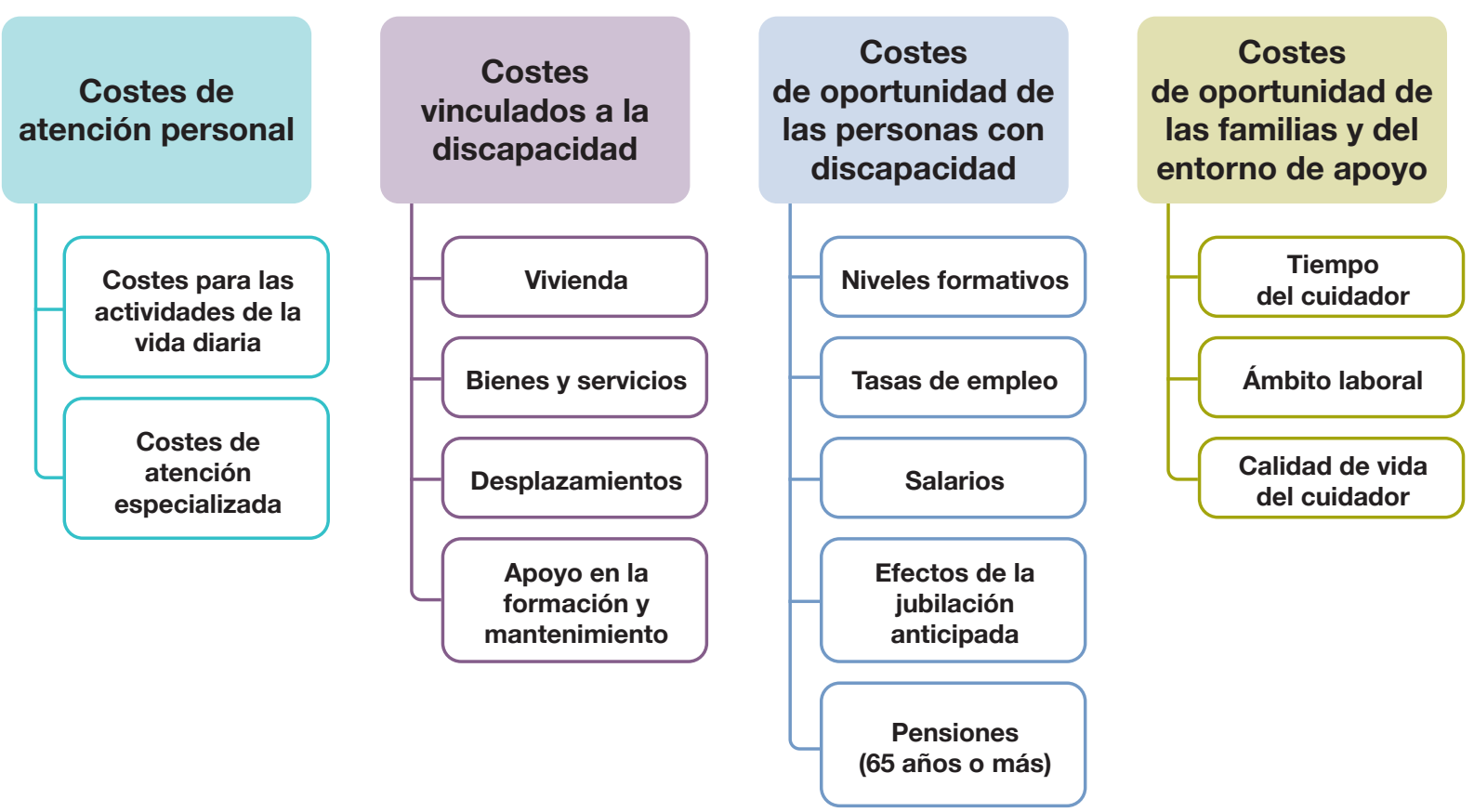

Fuente: elaboración propia.

Los dos primeros bloques de la figura 1 recogen los costes identificados como directos y contemplan costes de atención personal y costes asociados íntimamente a la situación de discapacidad. Los costes indirectos se han desagregado entre los costes de oportunidad vinculados a la persona con discapacidad y los imputables a su entorno más inmediato (cuidador principal). A continuación se explican con un mayor detalle las distintas tipologías de costes evaluadas.

\subsection{Costes de atención personal}

Los costes de atención personal van dirigidos a preservar y mantener un nivel adecuado de calidad de vida, contribuyendo a mejorar el estado de salud de la persona con discapacidad, así como previniendo potenciales situaciones de empeoramiento.

- Los costes de atención personal incluyen, por un lado, el apoyo requerido para la realización de las actividades de la vida diaria y, por el otro, los servicios de atención especializada. Se entiende por actividades de la vida diaria las actividades cotidianas como el hecho de levantarse de la cama, incorporarse de una silla, vestirse y desvestirse, comer, tareas de higiene personal, administración de la medicación. Su evaluación se ha realizado en base al número medio diario de horas requeridas para cada perfil de discapacidad, considerándose unos valores de 1,5 horas al día (necesidad de soporte considerable, en el caso de los perfiles DF1, DI1, DV2 y TM1), de 3 horas diarias (necesidad intensa de soporte, en los 
perfiles DF2, DI2, TM2 y DF3) y, finalmente, de 5 horas al día (necesidad muy intensa de soporte, para los perfiles DF3, DI3 y TM3) en base a la tipología y al grado de discapacidad y según las necesidades de soporte definidas por la escala alemana. Así mismo, se ha considerado un precio hora promedio de $9,34 €$, para el año $2017^{12}$.

- Los servicios de atención especializada son los que permiten o contribuyen a facilitar o mejorar las habilidades de las personas con discapacidad en su relación con el entorno laboral y social y contribuyen a paliar el dolor. Las distintas tipologías de atención especializada se han definido en función del perfil de discapacidad y del grado considerado. En el caso de las situaciones de discapacidad física se han considerado los servicios de atención de enfermería y/o de fisioterapia (en función del grado de discapacidad). Por lo que respecta a los perfiles de discapacidad intelectual, se han contemplado servicios de logopedia, psicoterapia, etc. En la discapacidad visual se han evaluado situaciones de soporte formativo y tiflotécnico (en el perfil de resto visual). En los perfiles de discapacidad auditiva, la atención especializada contempla los servicios de traducción de la lengua de signos o los servicios de transcripción. Finalmente, en las distintas clasificaciones asociadas al trastorno mental, se han computado servicios de soporte psicológico, de terapia ocupacional, etc. La valoración de tales servicios se ha basado en las remuneraciones promedio de las distintas categorías profesionales oscilando en una horquilla que oscila entre los $23 € /$ hora (servicios de enfermería) y los $53,3 € /$ hora (servicios de logopedia).

\subsection{Costes vinculados a la discapacidad}

Son cuatro los epígrafes considerados en este grupo de costes directos.

En primer lugar, los costes asociados a la adaptación de la vivienda que deben realizar las personas con algún tipo de discapacidad. Los elementos considerados y su coste están asociados al perfil de discapacidad objeto de análisis. Por lo que respecta a las personas con discapacidad física, se han contemplado los costes medios asociados al proceso de adaptación de la vivienda (instalación de rampa de acceso en el portal, remodelación del baño y de la cocina, habilitación de las zonas de circulación, instalaciones domóticas básicas). Se han tenido presentes los gastos asociados a la actualización o instalación de un ascensor en la vivienda. El período de amortización se ha estimado en 30 años en el caso de reformas en el inmueble y de 5 años para las instalaciones de domótica. Para los dos perfiles de discapacidad auditiva, se han contemplado los costes vinculados a la instalación de elementos de control y de seguridad (alarma antiincendios de flash, avisador de puerta). Asimismo, para los perfiles de discapacidad auditiva y los más graves de trastorno mental y de discapacidad intelectual, se han considerado costes de insonorización.

En segundo lugar se ha considerado el coste medio en bienes y servicios específicos relacionados con la situación de discapacidad. Nuevamente, los conceptos contemplados dependen de la tipología y del grado de discapacidad y el abanico de productos considerados es muy dispar. A continuación se identifican los más importantes.

12. El precio por hora, vinculado a las actividades de soporte de las actividades de la vida diaria, se ha establecido considerando la información extraída de la Encuesta Anual de Estructura Salarial en relación al salario base más los complementos estipulados para la categoría laboral de logopedas, trabajadores sociales, educadores sociales, diplomados universitarios de enfermería, terapeutas ocupacionales, etc. Dado que, según el informe del Área de Derechos Sociales - Ayuntamiento de Barcelona (2017) el 9,86\% de las personas con discapacidad residentes en Barcelona utilizan el Servicio de Atención Domiciliaria (SAD) y el coste por hora del mismo era de 16,91 $€$ en 2017, se ha calculado el precio hora promedio ponderando los dos valores anteriores. El resultado final determina el coste horario medio en un valor de $9,34 €$ (que es el utilizado en el proceso de valoración del coste de las actividades de la vida diaria). 
- Ayudas de carácter técnico vinculadas a higiene personal, transferencias, movilidad, etc. (en el caso de los perfiles de discapacidad física), mantenimiento del perro guía, ayudas ópticas, productos facilitadores de las actividades de la vida diaria, etc. (discapacidad visual).

- Informática adaptada, en los perfiles de discapacidad física y sensorial.

- Ortopedia, en los perfiles de discapacidad sensorial y física.

- Gastos adicionales en ropa, energía o vinculados al tiempo de ocio.

Seguidamente se han contemplado los costes asociados a desplazamientos, tanto en lo que respecta a la adaptación del vehículo particular como los recursos adicionales (mayor tiempo, necesidad de acompañante) vinculados a la movilidad.

Finalmente, se han evaluado los costes medios asociados a formación y mantenimiento por perfiles de discapacidad.

\subsection{Costes de oportunidad de las personas}

Dentro del grupo de costes indirectos, se han analizado e incorporado los costes de oportunidad de las personas con discapacidad, entendidos como el valor económico que comporta la reducción de alternativas que puedan tener. En este sentido, el cálculo del coste de oportunidad ha considerado las distintas implicaciones en el ámbito laboral que puedan ir asociadas a niveles de formación inferiores, a dificultades en el acceso al mercado laboral y, en correspondencia, a una menor tasa de participación y mayor tasa de paro y que acabarán repercutiendo en que los ingresos salariales percibidos sean inferiores.

La aproximación al coste de oportunidad de las personas se ha abordado comparando el salario que deberían percibir las personas con discapacidad con el salario percibido. Para el primero, atendiendo a que la distribución de la variable salarial no es simétrica y a que ni la media ni la mediana recogen las diferencias asociadas a la tipología de jornada o al distrito de residencia, se ha contemplado como referencia la mediana salarial considerando la distribución de la población con discapacidad en la ciudad de Barcelona en los diferentes distritos. Para el ajuste del salario percibido se han tenido en cuenta, atendiendo a los distintos perfiles de discapacidad evaluados, diferentes remuneraciones (salarios en el mercado ordinario o salarios en Centros Especiales de Trabajo) y situaciones de participación y de no participación en el mercado de trabajo.

A efectos del cálculo del coste de oportunidad de las personas que hayan participado en el mercado de trabajo, se han tenido en cuenta los efectos de la discapacidad en las jubilaciones anticipadas y en las correspondientes pensiones percibidas. Considerando la significativa heterogeneidad en la determinación de la edad a partir de la cual una persona con discapacidad empieza a envejecer, y en ausencia de información sobre la edad de jubilación de las personas con discapacidad, se ha recurrido a la legislación al efecto, según la cual la edad mínima de jubilación de las personas con un grado de discapacidad igual o superior al 65 por ciento es de 52 años. Para grados de discapacidad igual o superior al 45 por ciento se retrasa hasta los 56 años.

El agravio comparativo económico asociado a la jubilación anticipada se ha valorado como la diferencia acumulada (considerando la reducción en los años de vida laboral y la menor esperanza de vida) entre 
el salario ajustado a percibir en un puesto de trabajo en el mercado ordinario y la pensión por jubilación anticipada. Se ha anualizado el importe total acumulado entre la vida laboral media.

\subsection{Costes de oportunidad de las familias y del entorno de apoyo}

Contemplar el papel de atención y de soporte en las actividades de la vida diaria a las personas con discapacidad por parte de cuidadores informales, habitualmente familiares, y su correspondiente valoración económica resulta esencial en tanto que complementa la asistencia especializada e incluso actúa como un sustituto de la atención formal.

La aproximación económica al efecto indirecto sobre el entorno familiar de apoyo, como coste de oportunidad para las familias, ha considerado el impacto del tiempo dedicado (contabilizado a través de la valorización de las horas como cuidador) y las menores oportunidades en el entorno laboral (participación en el mercado de trabajo, dificultades en la promoción laboral o formación). Igualmente, se ha atendido a la incidencia sobre la calidad de vida del cuidador principal (en salud y tiempo de ocio) ${ }^{13}$.

A fin de evitar una doble contabilización, para el coste de oportunidad del tiempo de los cuidadores se han computado las horas de atención asumidas por miembros del entorno que superen las ya consideradas como de atención a actividades de la vida diaria en los perfiles considerados.

Para el cálculo de la afectación sobre las oportunidades laborales del cuidador se ha procedido a comparar el coste medio de la atención de una persona ocupada en la atención de otra persona con discapacidad, equivalente al salario que debería percibir como cuidador, con la estimación del salario medio que tendría este cuidador si no asumiese esta labor, distinguiendo entre 3 posibles niveles salariales (alto, medio y bajo) y ajustando cada diferencia por los porcentajes de contratación de cada nivel de ocupación. Finalmente, la diferencia media se ha ajustado atendiendo al porcentaje de cuidadores ocupados y a la tasa de ocupación a tiempo completo en Cataluña.

La afectación sobre la calidad de vida del cuidador principal cuando es asumida por un familiar no es neutra y acaba repercutiendo sobre su salud. No obstante, no se ha computado como coste indirecto atendiendo al importante elemento de subjetividad que dificulta su valoración económica. Por el contrario, se ha valorizado la reducción o supresión del tiempo de ocio del cuidador en aquellos perfiles de discapacidad en los cuales los tiempos de atención y soporte superan los ya considerados.

\subsection{Ingresos}

En esta sección se analizan las distintas prestaciones, ayudas, bonificaciones y/o deducciones que las personas con discapacidad y sus familias son susceptibles de percibir. Su naturaleza es muy diversa y suele estar en función de los ingresos y/o del nivel de renta de la persona con discapacidad y su entorno más próximo. La figura 2 aproxima las 5 tipologías de ayudas consideradas en el presente estudio.

13. Véase van den Berg et al. (2004) para una amplia revisión de los métodos y aplicaciones de valoración económica de la atención informal. Imserso (2004) ofrece una caracterización de los ámbitos afectados y de las consecuencias negativas para los cuidadores informales de personas con discapacidad. 


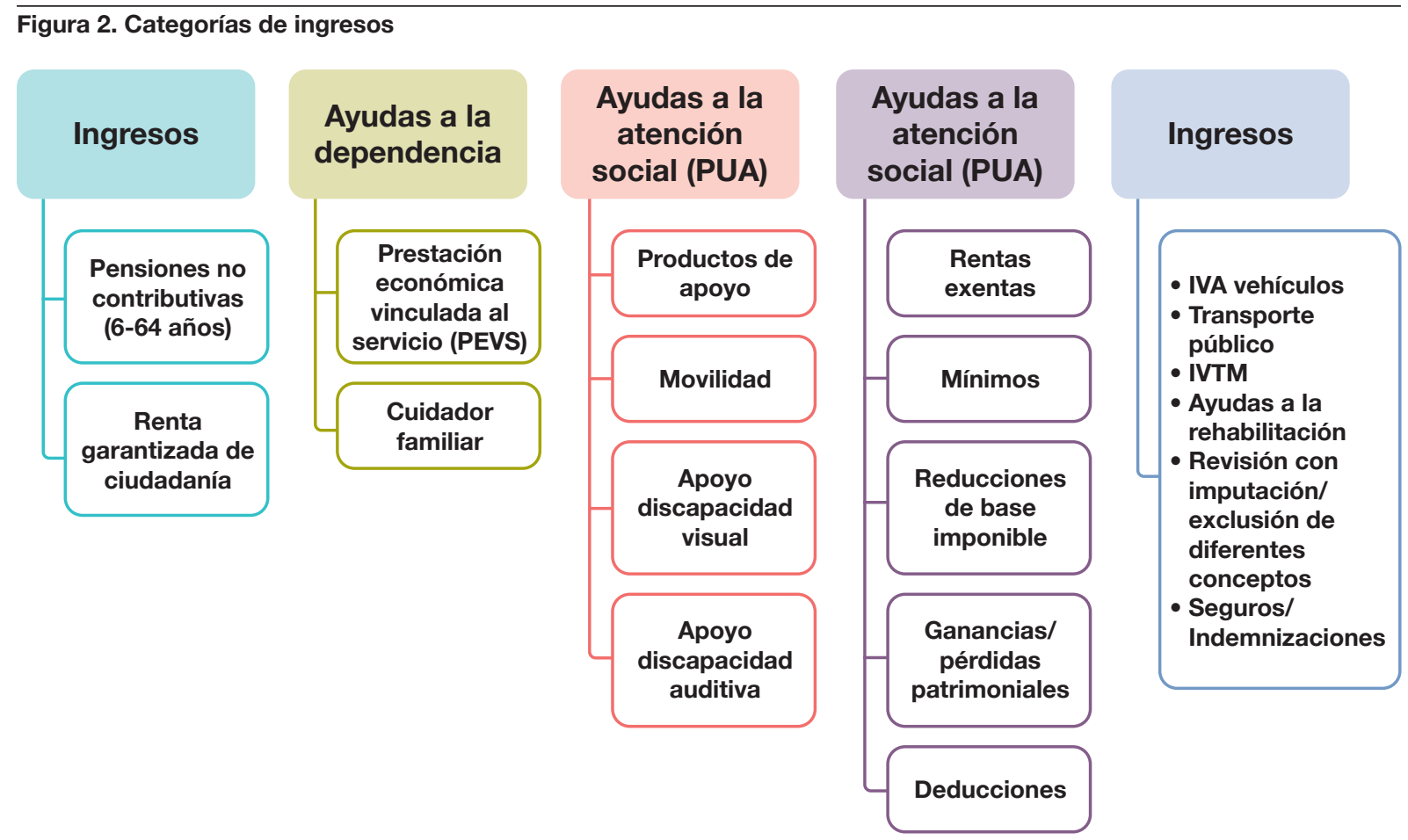

Fuente: elaboración propia.

En el bloque específico de ingresos se han considerado las pensiones no contributivas percibidas por personas con discapacidad para cada uno de los perfiles definidos. Se ha descartado la incidencia de la renta garantizada de ciudadanía (RGC) por su impacto marginal.

Las ayudas a la dependencia incluyen dos tipologías de elementos de soporte económico: la prestación económica vinculada al servicio (PEVS), un recurso que facilita el suministro de ayudas a la persona en situación de dependencia cuando no es posible acceder a este servicio en el sector público, y la prestación para el apoyo al entorno familiar y a cuidadores no profesionales, que se otorga a familiares hasta tercer grado que ejercen de cuidadores desde hace más de un año en el momento en el que se procesa la solicitud de ayuda.

Para complementar el capítulo de ayudas a la dependencia, se han analizado los elementos del Programa de ayudas de atención social (PUA) otorgadas por el departamento competente en temas de discapacidad de la Generalitat de Catalunya, para sufragar la adquisición de productos de apoyo y, también, las ayudas pagadas en concepto de facilitación de la movilidad, evaluando los importes pagados en el marco del PUA 2017 a personas con discapacidad residentes en la ciudad de Barcelona, por concepto y por tipología de discapacidad.

En el capítulo de las deducciones, se ha aproximado el efecto de la discapacidad, en términos medios, en el proceso de cálculo de los beneficios fiscales generados, de acuerdo con la Ley del impuesto sobre la renta de las personas físicas (IRPF) en el ejercicio fiscal 2017. 
Finalmente, se ha analizado y evaluado el impacto económico de otras deducciones, prestaciones y ayudas diversas: la subvención de prótesis y ortesis, la reducción del IVA por la compra de un vehículo, la exención del impuesto de matriculación, la reducción de precios en el transporte público, la exención y bonificación del impuesto de vehículos de tracción mecánica, la exención de la tasa por censar un perro guía, la exención y reducción en el copago farmacéutico, la subvención de productos farmacéuticos excluidos de la Seguridad Social, servicios de soporte a los cuidadores principales, ayudas para la rehabilitación de edificios de uso residencial y de viviendas en Barcelona, ayudas vinculadas a desplazamientos en coche, seguros frente a situaciones de discapacidad sobrevenidas, etc. Los valores estimados de las distintas ayudas se han ponderado en base al porcentaje de la población con discapacidad de la ciudad de Barcelona que se estima pudiera ser beneficiaria de cada una de ellas.

\section{Incidencia de la edad en el cálculo del agravio comparativo económico}

La correlación entre edad y proceso de envejecimiento y situaciones de discapacidad es clara. No obstante, las relaciones de causalidad entre unas y otras se mezclan y a menudo aparecen desdibujadas. En este estudio se ha optado por evaluar el agravio comparativo económico de las personas con discapacidad que son mayores de 65 años de manera diferenciada. Si bien metodológicamente se ha abordado el cálculo evaluando las mismas tipologías de costes y de ingresos, se ha procedido a su reescalado (en algunas ocasiones al alza y en otras a la baja) para adaptarlos a las circunstancias específicas de este grupo de personas.

Los cambios y ajustes incorporados que se han contemplado son:

- aumento de las necesidades de soporte en las actividades de la vida diaria;

- cambios en la atención especializada (supresión de algunas partidas);

- imputación de adaptaciones en la vivienda a todos los perfiles de discapacidad;

- cambios en las imputaciones de costes vinculados a la partida "bienes y servicios" (reducción de costes vinculados a informática adaptada, incremento de costes vinculados a partidas de movilidad, etc.);

- reducción de los costes vinculados a desplazamientos;

- reducción de los costes de oportunidad de las personas y aumento de los del entorno.

\section{Resultados}

Las siguientes tablas detallan, por un lado, las diferentes tipologías de costes y sus correspondientes rúbricas de gasto, así como los importes imputados a los trece perfiles de discapacidad evaluados, diferenciando entre los 6 y 64 años y de 65 o más años. Igualmente, se relacionan los diferentes conceptos de ingresos y los correspondientes importes atribuidos para la misma clasificación de perfiles de discapacidad. 
Finalmente, y como diferencia entre ambos conceptos, se incluye el ajuste del correspondiente agravio comparativo económico.

\begin{tabular}{|c|c|c|c|c|c|c|c|c|c|}
\hline \multirow{3}{*}{$\begin{array}{l}\text { PERFIL DE } \\
\text { DISCAPACIDAD }\end{array}$} & \multicolumn{8}{|c|}{ TIPOLOGÍAS DE COSTES } & \multirow{3}{*}{$\begin{array}{l}\text { COSTES } \\
\text { TOTALES }\end{array}$} \\
\hline & \multicolumn{2}{|c|}{$\begin{array}{l}\text { COSTES DE ATENCIÓN } \\
\text { PERSONAL }\end{array}$} & \multicolumn{4}{|c|}{ COSTES ADICIONALES VINCULADOS A LA DISCAPACIDAD } & \multirow{2}{*}{$\begin{array}{l}\text { Costes de } \\
\text { oportunidad } \\
\text { de las } \\
\text { personas }\end{array}$} & \multirow{2}{*}{$\begin{array}{l}\text { Costes de } \\
\text { oportunidad } \\
\text { del entorno }\end{array}$} & \\
\hline & $\begin{array}{c}\text { Actividades } \\
\text { de la vida } \\
\text { diaria }\end{array}$ & $\begin{array}{c}\text { Atención } \\
\text { especializada }\end{array}$ & Vivienda & $\begin{array}{l}\text { Bienes y } \\
\text { servicios }\end{array}$ & Desplazamientos & $\begin{array}{c}\text { Soporte } \\
\text { formativo y } \\
\text { mantenimiento }\end{array}$ & & & \\
\hline \multicolumn{10}{|c|}{ FísICA } \\
\hline DF1 & $5.113,65 €$ & $1.196,00 €$ & $635,57 €$ & $4.847,76 €$ & $3.481,23 €$ & $2.366,16 €$ & $14.617,77 €$ & $2.812,13 €$ & $35.070,27 €$ \\
\hline DF2 & $10.227,30 €$ & $8.131,00 €$ & $635,57 €$ & $5.775,77 €$ & $8.837,16 €$ & $2.410,17 €$ & $19.401,28 €$ & $2.812,13 €$ & $58.230,37 €$ \\
\hline DF3 & $17.045,50 €$ & $8.131,00 €$ & $635,57 €$ & $8.466,77 €$ & $9.728,09 €$ & $3.626,25 €$ & $27.671,65 €$ & $27.216,12 €$ & $102.520,96 €$ \\
\hline \multicolumn{10}{|c|}{ INTELECTUAL } \\
\hline DI1 & $5.113,65 €$ & $2.399,80 €$ & $0,00 €$ & $1.925,93 €$ & $0,00 €$ & $2.572,88 €$ & $14.617,77 €$ & $2.812,13 €$ & $29.442,17 €$ \\
\hline DI2 & $10.227,30 €$ & $2.399,80 €$ & $0,00 €$ & $1.925,93 €$ & $5.635,96 €$ & $2.616,89 €$ & $19.401,28 €$ & $2.812,13 €$ & $45.019,30 €$ \\
\hline DI3 & $17.045,50 €$ & $2.399,80 €$ & $83,00 €$ & $3.307,18 €$ & $5.635,96 €$ & $3.832,97 €$ & $27.671,65 €$ & $27.216,12 €$ & $87.192,19 €$ \\
\hline \multicolumn{10}{|c|}{ VISUAL } \\
\hline Resto visual & $0,00 €$ & $2.399,80 €$ & $0,00 €$ & $3.924,07 €$ & $2.601,95 €$ & $2.438,01 €$ & $14.617,77 €$ & $2.812,13 €$ & $28.793,72 €$ \\
\hline Ceguera total & $5.113,65 €$ & $0,00 €$ & $0,00 €$ & $5.293,34 €$ & $4.480,60 €$ & $2.482,01 €$ & $19.401,28 €$ & $2.812,13 €$ & $39.583,01 €$ \\
\hline \multicolumn{10}{|c|}{ AUDITIVA } \\
\hline Lengua oral & $0,00 €$ & $4.620,00 €$ & $272,00 €$ & $2.292,49 €$ & $0,00 €$ & $2.502,73 €$ & $14.617,77 €$ & $2.812,13 €$ & $27.117,12 €$ \\
\hline $\begin{array}{l}\text { Lengua de } \\
\text { signos }\end{array}$ & $0,00 €$ & $4.620,00 €$ & $189,00 €$ & $1.809,16 €$ & $0,00 €$ & $2.502,73 €$ & $14.617,77 €$ & $2.812,13 €$ & $26.550,79 €$ \\
\hline \multicolumn{10}{|c|}{ TRASTORNO MENTAL } \\
\hline TM1 & $5.113,65 €$ & $910,00 €$ & $0,00 €$ & $1.925,93 €$ & $0,00 €$ & $2.365,84 €$ & $14.617,77 €$ & $2.812,13 €$ & $27.745,32 €$ \\
\hline TM2 & $10.227,30 €$ & $1.820,00 €$ & $0,00 €$ & $1.925,93 €$ & $3.757,31 €$ & $2.365,84 €$ & $19.401,28 €$ & $2.812,13 €$ & $42.309,79 €$ \\
\hline TM3 & $17.045,50 €$ & $7.280,00 €$ & $83,00 €$ & $3.307,18 €$ & $3.757,31 €$ & $3.537,92 €$ & $27.671,65 €$ & $27.216,12 €$ & $89.898,68 €$ \\
\hline
\end{tabular}

Fuente: elaboración propia. 


\begin{tabular}{|c|c|c|c|c|c|}
\hline $\begin{array}{l}\text { PERFIL DE } \\
\text { DISCAPACIDAD }\end{array}$ & $\begin{array}{l}\text { TOTAL COSTES } \\
\text { DIRECTOS }\end{array}$ & $\begin{array}{l}\text { TOTAL COSTES } \\
\text { INDIRECTOS }\end{array}$ & $\begin{array}{l}\text { COSTES } \\
\text { TOTALES }\end{array}$ & $\begin{array}{l}\% \text { COSTES } \\
\text { DIRECTOS }\end{array}$ & $\begin{array}{l}\% \text { COSTES } \\
\text { INDIRECTOS }\end{array}$ \\
\hline \multicolumn{6}{|c|}{ FísıCA } \\
\hline DF1 & $17.640,37 €$ & $17.429,90 €$ & $35.070,27 €$ & $50,30 \%$ & $49,70 \%$ \\
\hline DF2 & $36.016,96 €$ & $22.213,41 €$ & $58.230,37 €$ & $61,85 \%$ & $38,15 \%$ \\
\hline DF3 & $47.633,19 €$ & $54.887,77 €$ & $102.520,96 €$ & $46,46 \%$ & $53,54 \%$ \\
\hline \multicolumn{6}{|c|}{ INTELECTUAL } \\
\hline DI1 & $12.012,27 €$ & $17.429,90 €$ & $29.442,17 €$ & $40,80 \%$ & $59,20 \%$ \\
\hline DI2 & $22.805,89 €$ & $22.213,41 €$ & $45.019,30 €$ & $50,66 \%$ & $49,34 \%$ \\
\hline DI3 & $32.304,42 €$ & $54.887,77 €$ & $87.192,19 €$ & $37,05 \%$ & $62,95 \%$ \\
\hline \multicolumn{6}{|c|}{ VISUAL } \\
\hline Resto visual & $11.363,82 €$ & $17.429,90 €$ & $28.793,72 €$ & $39,47 \%$ & $60,53 \%$ \\
\hline Ceguera total & $17.369,60 €$ & $22.213,41 €$ & $39.583,01 €$ & $43,88 \%$ & $56,12 \%$ \\
\hline \multicolumn{6}{|c|}{ AUDITIVA } \\
\hline Lengua oral & $9.687,22 €$ & $17.429,90 €$ & $27.117,12 €$ & $35,72 \%$ & $64,28 \%$ \\
\hline Lengua de signos & $9.120,89 €$ & $17.429,90 €$ & $26.550,79 €$ & $34,35 \%$ & $65,65 \%$ \\
\hline \multicolumn{6}{|c|}{ TRASTORNO MENTAL } \\
\hline TM1 & $10.315,42 €$ & $17.429,90 €$ & $27.745,32 €$ & $37,18 \%$ & $62,82 \%$ \\
\hline TM2 & $20.096,38 €$ & $22.213,41 €$ & $42.309,79 €$ & $47,50 \%$ & $52,50 \%$ \\
\hline TM3 & $35.010,91 €$ & $54.887,77 €$ & $89.898,68 €$ & $38,94 \%$ & $61,06 \%$ \\
\hline
\end{tabular}

Fuente: elaboración propia. 


\begin{tabular}{|c|c|c|c|c|c|c|c|c|c|}
\hline \multirow{3}{*}{$\begin{array}{l}\text { PERFIL DE } \\
\text { DISCAPACIDAD }\end{array}$} & \multicolumn{8}{|c|}{ TIPOLOGÍAS DE COSTES } & \multirow{3}{*}{$\begin{array}{l}\text { COSTES } \\
\text { TOTALES }\end{array}$} \\
\hline & \multicolumn{2}{|c|}{$\begin{array}{c}\text { COSTES DE ATENCIÓN } \\
\text { PERSONAL }\end{array}$} & \multicolumn{4}{|c|}{ COSTES ADICIONALES VINCULADOS A LA DISCAPACIDAD } & \multirow{2}{*}{$\begin{array}{l}\text { Costes de } \\
\text { oportunidad } \\
\text { de las } \\
\text { personas }\end{array}$} & \multirow{2}{*}{$\begin{array}{l}\text { Costes de } \\
\text { oportunidad } \\
\text { del entorno }\end{array}$} & \\
\hline & $\begin{array}{c}\text { Actividades } \\
\text { de la vida } \\
\text { diaria }\end{array}$ & $\begin{array}{c}\text { Atención } \\
\text { especializada }\end{array}$ & Vivienda & $\begin{array}{l}\text { Bienes y } \\
\text { servicios }\end{array}$ & Desplazamientos & $\begin{array}{c}\text { Soporte } \\
\text { formativo y } \\
\text { mantenimiento }\end{array}$ & & & \\
\hline \multicolumn{10}{|c|}{ FísıCA } \\
\hline DF1 & $5.181,83 €$ & $1.196,00 €$ & $1.029,14 €$ & $4.117,44 €$ & $3.155,21 €$ & $2.366,16 €$ & $3.628,81 €$ & $2.812,13 €$ & $23.486,72 €$ \\
\hline DF2 & $12.613,67 €$ & $8.131,00 €$ & $1.029,14 €$ & $4.530,65 €$ & $6.034,01 €$ & $2.410,17 €$ & $10.130,09 €$ & $2.812,13 €$ & $47.690,86 €$ \\
\hline DF3 & $20.079,60 €$ & $8.131,00 €$ & $1.029,14 €$ & $5.718,18 €$ & $6.034,01 €$ & $3.626,25 €$ & $14.166,72 €$ & $28.589,76 €$ & $87.374,67 €$ \\
\hline \multicolumn{10}{|c|}{ INTELECTUAL } \\
\hline DI1 & $5.181,83 €$ & $0,00 €$ & $653,81 €$ & $1.559,46 €$ & $2.356,78 €$ & $2.572,88 €$ & $3.628,81 €$ & $2.812,13 €$ & $18.765,70 €$ \\
\hline DI2 & $12.613,67 €$ & $0,00 €$ & $653,81 €$ & $1.559,46 €$ & $5.973,19 €$ & $2.616,89 €$ & $10.130,09 €$ & $2.812,13 €$ & $36.359,23 €$ \\
\hline DI3 & $20.079,60 €$ & $0,00 €$ & $820,81 €$ & $2.940,71 €$ & $5.973,19 €$ & $3.832,97 €$ & $14.166,72 €$ & $28.589,76 €$ & $76.403,75 €$ \\
\hline \multicolumn{10}{|c|}{ VISUAL } \\
\hline Resto visual & $5.181,83 €$ & $0,00 €$ & $653,81 €$ & $2.975,62 €$ & $2.897,60 €$ & $2.438,01 €$ & $3.628,81 €$ & $2.812,13 €$ & $20.587,80 €$ \\
\hline Ceguera total & $5.181,83 €$ & $0,00 €$ & $653,81 €$ & $3.111,19 €$ & $4.776,25 €$ & $2.482,01 €$ & $10.130,09 €$ & $2.812,13 €$ & $29.147,31 €$ \\
\hline \multicolumn{10}{|c|}{ AUDITIVA } \\
\hline Lengua oral & $5.181,83 €$ & $4.620,00 €$ & $1.009,81 €$ & $2.018,20 €$ & $2.356,78 €$ & $2.502,73 €$ & $3.628,81 €$ & $2.812,13 €$ & $24.130,29 €$ \\
\hline $\begin{array}{l}\text { Lengua de } \\
\text { signos }\end{array}$ & $5.181,83 €$ & $4.620,00 €$ & $842,81 €$ & $1.534,87 €$ & $2.356,78 €$ & $2.502,73 €$ & $3.628,81 €$ & $2.812,13 €$ & $23.479,96 €$ \\
\hline \multicolumn{10}{|c|}{ TRASTORNO MENTAL } \\
\hline TM1 & $5.181,83 €$ & $0,00 €$ & $653,81 €$ & $1.559,46 €$ & $2.356,78 €$ & $2.365,84 €$ & $3.628,81 €$ & $2.812,13 €$ & $18.558,65 €$ \\
\hline TM2 & $12.613,67 €$ & $0,00 €$ & $653,81 €$ & $1.559,46 €$ & $4.235,43 €$ & $2.365,84 €$ & $10.130,09 €$ & $2.812,13 €$ & $34.370,43 €$ \\
\hline TM3 & $20.079,60 €$ & $0,00 €$ & $820,81 €$ & $2.940,71 €$ & $4.235,43 €$ & $3.537,92 €$ & $14.166,72 €$ & $28.589,76 €$ & $74.370,95 €$ \\
\hline
\end{tabular}

Fuente: elaboración propia. 


\begin{tabular}{|c|c|c|c|c|c|}
\hline $\begin{array}{l}\text { PERFIL DE } \\
\text { DISCAPACIDAD }\end{array}$ & $\begin{array}{l}\text { TOTAL COSTES } \\
\text { DIRECTOS }\end{array}$ & $\begin{array}{l}\text { TOTAL COSTES } \\
\text { INDIRECTOS }\end{array}$ & $\begin{array}{l}\text { COSTES } \\
\text { TOTALES }\end{array}$ & $\begin{array}{l}\% \text { COSTES } \\
\text { DIRECTOS }\end{array}$ & $\begin{array}{l}\text { \% COSTES } \\
\text { INDIRECTOS }\end{array}$ \\
\hline \multicolumn{6}{|c|}{ FíSICA } \\
\hline DF1 & $17.045,78 €$ & $6.440,94 €$ & $23.486,72 €$ & $72,58 \%$ & $27,42 \%$ \\
\hline DF2 & $34.748,64 €$ & $12.942,22 €$ & $47.690,86 €$ & $72,86 \%$ & $27,14 \%$ \\
\hline DF3 & $44.618,19 €$ & $42.756,48 €$ & $87.374,67 €$ & $51,07 \%$ & $48,93 \%$ \\
\hline \multicolumn{6}{|c|}{ INTELECTUAL } \\
\hline DI1 & $12.324,76 €$ & $6.440,94 €$ & $18.765,70 €$ & $65,68 \%$ & $34,32 \%$ \\
\hline DI2 & $23.417,01 €$ & $12.942,22 €$ & $36.359,23 €$ & $64,40 \%$ & $35,60 \%$ \\
\hline DI3 & $33.647,27 €$ & $42.756,48 €$ & $76.403,75 €$ & $44,04 \%$ & $55,96 \%$ \\
\hline \multicolumn{6}{|c|}{ VISUAL } \\
\hline Resto visual & $14.146,86 €$ & $6.440,94 €$ & $20.587,80 €$ & $68,71 \%$ & $31,29 \%$ \\
\hline Ceguera total & $16.205,09 €$ & $12.942,22 €$ & $29.147,31 €$ & $55,60 \%$ & $44,40 \%$ \\
\hline \multicolumn{6}{|c|}{ AUDITIVA } \\
\hline Lengua oral & $17.689,35 €$ & $6.440,94 €$ & $24.130,29 €$ & $73,31 \%$ & $26,69 \%$ \\
\hline Lengua de signos & $17.039,02 €$ & $6.440,94 €$ & $23.479,96 €$ & $72,57 \%$ & $27,43 \%$ \\
\hline \multicolumn{6}{|c|}{ TRASTORNO MENTAL } \\
\hline TM1 & $12.117,71 €$ & $6.440,94 €$ & $18.558,65 €$ & $65,29 \%$ & $34,71 \%$ \\
\hline TM2 & $21.428,21 €$ & $12.942,22 €$ & $34.370,43 €$ & $62,34 \%$ & $37,66 \%$ \\
\hline TM3 & $31.614,47 €$ & $42.756,48 €$ & $74.370,95 €$ & $42,51 \%$ & $57,49 \%$ \\
\hline
\end{tabular}

Fuente: elaboración propia. 


\begin{tabular}{|c|c|c|c|c|c|c|c|c|c|c|}
\hline \multirow{3}{*}{$\begin{array}{l}\text { PERFIL DE } \\
\text { DISCAPACIDAD }\end{array}$} & \multicolumn{9}{|c|}{ TIPOLOGÍAS DE AYUDAS, INGRESOS, BONIFICACIONES } & \multirow{3}{*}{$\begin{array}{c}\text { AYUDAS, } \\
\text { INGRESOS, } \\
\text { BONIFICACIONES } \\
\text { TOTALES }\end{array}$} \\
\hline & \multirow[b]{2}{*}{$\begin{array}{c}\text { Pensiones } \\
\text { no } \\
\text { contributivas }\end{array}$} & \multirow[b]{2}{*}{$\begin{array}{c}\text { Ayudas a la } \\
\text { dependencia }\end{array}$} & \multirow{2}{*}{$\begin{array}{c}\text { Programa } \\
\text { Ayudas } \\
\text { Atención } \\
\text { Social } \\
\text { (PUA) }\end{array}$} & \multirow{2}{*}{$\begin{array}{c}\text { Deducciones } \\
\text { IRPF }\end{array}$} & \multicolumn{5}{|c|}{ Otras tipologías de ayudas e ingresos } & \\
\hline & & & & & $\begin{array}{l}\text { Relacionados } \\
\text { con los } \\
\text { vehículos }\end{array}$ & $\begin{array}{c}\text { Transporte } \\
\text { público }\end{array}$ & $\begin{array}{c}\text { Ayudas } \\
\text { ámbito } \\
\text { sanitario }\end{array}$ & $\begin{array}{c}\text { Rehabilitación } \\
\text { viviendas } \\
\text { y acceso } \\
\text { edificios }\end{array}$ & $\begin{array}{c}\text { Seguros e } \\
\text { indemnizaciones }\end{array}$ & \\
\hline DF1 & - & $25,75 €$ & $5,04 €$ & $1.274,64 €$ & $423,93 €$ & $55,79 €$ & $73,74 €$ & $181,84 €$ & $259,48 €$ & $2.300,21 €$ \\
\hline DF2 & $1.334,90 €$ & $223,53 €$ & $5,04 €$ & $1.274,64 €$ & $423,93 €$ & $89,61 €$ & $73,74 €$ & $181,84 €$ & $736,62 €$ & $4.343,85 €$ \\
\hline DF3 & $2.002,34 €$ & $2.047,71 €$ & $5,04 €$ & $1.274,64 €$ & $423,93 €$ & $89,61 €$ & $73,74 €$ & $181,84 €$ & $1.109,23 €$ & $7.208,08 €$ \\
\hline \multicolumn{11}{|c|}{ INTELECTUAL } \\
\hline DI3 & $2.002,34 €$ & $3.224,57 €$ & $3,98 €$ & $1.274,64 €$ & $423,93 €$ & $89,61 €$ & $0,45 €$ & - & $1.109,23 €$ & $8.128,75 €$ \\
\hline \multicolumn{11}{|c|}{ VISUAL } \\
\hline Resto visual & - & $104,53 €$ & $3,36 €$ & $1.274,64 €$ & $310,89 €$ & $89,61 €$ & $73,74 €$ & - & $512,97 €$ & $2.369,74 €$ \\
\hline Ceguera total & $1.334,90 €$ & $589,48 €$ & $3,36 €$ & $1.274,64 €$ & $310,89 €$ & $89,61 €$ & $73,74 €$ & - & $1.109,23 €$ & $4.785,85 €$ \\
\hline \multicolumn{11}{|c|}{ AUDITIVA } \\
\hline Lengua oral & - & $112,45 €$ & $83,78 €$ & $1.274,64 €$ & $113,04 €$ & $55,79 €$ & $73,74 €$ & - & $533,66 €$ & $2.247,10 €$ \\
\hline $\begin{array}{l}\text { Lengua de } \\
\text { signos }\end{array}$ & - & $112,45 €$ & $83,78 €$ & $1.274,64 €$ & $113,04 €$ & $55,79 €$ & $73,74 €$ & - & $533,66 €$ & $2.247,10 €$ \\
\hline \multicolumn{11}{|c|}{ TRASTORNO MENTAL } \\
\hline
\end{tabular}

Fuente: elaboración propia. 


\begin{tabular}{|c|c|c|c|c|c|c|c|c|c|}
\hline \multirow{2}{*}{$\begin{array}{l}\text { PERFIL DE } \\
\text { DISCAPACIDAD }\end{array}$} & \multirow[b]{2}{*}{$\begin{array}{c}\text { Ayudas a la } \\
\text { dependencia }\end{array}$} & \multirow{2}{*}{$\begin{array}{c}\text { Programa } \\
\text { Ayudas } \\
\text { Atención } \\
\text { Social } \\
\text { (PUA) }\end{array}$} & \multirow{2}{*}{$\begin{array}{c}\text { Deducciones } \\
\text { IRPF }\end{array}$} & \multicolumn{5}{|c|}{ Otras tipologías de ayudas e ingresos } & \multirow{2}{*}{$\begin{array}{c}\text { AYUDAS, } \\
\text { INGRESOS, } \\
\text { BONIFICACIONES } \\
\text { TOTALES }\end{array}$} \\
\hline & & & & \begin{tabular}{|c|} 
Relacionados \\
con los \\
vehículos
\end{tabular} & $\begin{array}{c}\text { Transporte } \\
\text { público }\end{array}$ & $\begin{array}{c}\text { Ayudas } \\
\text { ámbito } \\
\text { sanitario }\end{array}$ & $\begin{array}{c}\text { Rehabilitación } \\
\text { viviendas } \\
\text { y acceso } \\
\text { edificios }\end{array}$ & $\begin{array}{c}\text { Seguros e } \\
\text { indemnizaciones }\end{array}$ & \\
\hline \multicolumn{10}{|c|}{ FísıCA } \\
\hline DF1 & $242,49 €$ & $5,04 €$ & $1.274,64 €$ & $423,93 €$ & $55,79 €$ & $73,74 €$ & $181,84 €$ & $556,64 €$ & $2.814,11 €$ \\
\hline DF2 & $631,37 €$ & $5,04 €$ & $1.274,64 €$ & $423,93 €$ & $89,61 €$ & $73,74 €$ & $181,84 €$ & $1.048,80 €$ & $3.728,97 €$ \\
\hline DF3 & $2.088,85 €$ & $5,04 €$ & $1.274,64 €$ & $423,93 €$ & $89,61 €$ & $73,74 €$ & $181,84 €$ & $1.671,70 €$ & $5.809,35 €$ \\
\hline \multicolumn{10}{|c|}{ INTELECTUAL } \\
\hline DI1 & $632,87 €$ & $3,98 €$ & $1.274,64 €$ & $113,04 €$ & $55,79 €$ & $0,45 €$ & - & $556,64 €$ & $2.637,41 €$ \\
\hline DI2 & $1.635,65 €$ & $3,98 €$ & $1.274,64 €$ & $113,04 €$ & $89,61 €$ & $0,45 €$ & - & $1.048,80 €$ & $4.166,17 €$ \\
\hline DI3 & $2.701,42 €$ & $3,98 €$ & $1.274,64 €$ & $423,93 €$ & $89,61 €$ & $0,45 €$ & - & $1.671,70 €$ & $6.165,73 €$ \\
\hline \multicolumn{10}{|c|}{ VISUAL } \\
\hline Resto visual & $629,80 €$ & $3,36 €$ & $1.274,64 €$ & $310,89 €$ & $89,61 €$ & $73,74 €$ & - & $1.048,80 €$ & $3.430,84 €$ \\
\hline Ceguera total & $1.253,02 €$ & $3,36 €$ & $1.274,64 €$ & $310,89 €$ & $89,61 €$ & $73,74 €$ & - & $1.671,70 €$ & $4.676,96 €$ \\
\hline \multicolumn{10}{|c|}{ AUDITIVA } \\
\hline Lengua oral & $678,71 €$ & $83,78 €$ & $1.274,64 €$ & $113,04 €$ & $55,79 €$ & $73,74 €$ & - & $1.075,60 €$ & $3.355,30 €$ \\
\hline $\begin{array}{l}\text { Lengua de } \\
\text { signos }\end{array}$ & $678,71 €$ & $83,78 €$ & $1.274,64 €$ & $113,04 €$ & $55,79 €$ & $73,74 €$ & - & $1.075,60 €$ & $3.355,30 €$ \\
\hline \multicolumn{10}{|c|}{ TRASTORNO MENTAL } \\
\hline TM1 & $316,24 €$ & $3,98 €$ & $1.274,64 €$ & $0,00 €$ & $55,79 €$ & $0,45 €$ & - & $556,64 €$ & $2.207,74 €$ \\
\hline TM2 & $868,02 €$ & $3,98 €$ & $1.274,64 €$ & $0,00 €$ & $89,61 €$ & $0,45 €$ & - & $1.048,80 €$ & $3.285,50 €$ \\
\hline TM3 & $2.883,74 €$ & $3,98 €$ & $1.274,64 €$ & $310,89 €$ & $89,61 €$ & $0,45 €$ & - & $1.671,70 €$ & $6.235,01 €$ \\
\hline
\end{tabular}

Fuente: elaboración propia. 


\begin{tabular}{|c|c|c|c|c|}
\hline PERFIL DE DISCAPACIDAD & $\begin{array}{c}\text { AGRAVIO } \\
\text { COMPARATIVO } \\
\text { ECONÓMICO } \\
\text { TOTAL } \\
\text { (6 a } 64 \text { años) }\end{array}$ & $\begin{array}{l}\text { AGRAVIO } \\
\text { COMPARATIVO } \\
\text { ECONÓMICO } \\
\text { SOBRE COSTES } \\
\text { DIRECTOS } \\
\text { (6 a } 64 \text { años) }\end{array}$ & $\begin{array}{c}\text { AGRAVIO } \\
\text { COMPARATIVo } \\
\text { ECONÓMICO } \\
\text { TOTAL (65 años o } \\
\text { más) }\end{array}$ & $\begin{array}{c}\text { AGRAVIO } \\
\text { COMPARATIVO } \\
\text { ECONÓMICO } \\
\text { SOBRE COSTES } \\
\text { DIRECTOS ( } 65 \text { años } \\
\text { o más) }\end{array}$ \\
\hline \multicolumn{5}{|c|}{ FíSICA } \\
\hline Discapacidad física 1 (DF1) & $32.770,06 €$ & $15.340,16 €$ & $20.672,61 €$ & $14.231,67 €$ \\
\hline Discapacidad física 2 (DF2) & $53.886,52 €$ & $31.673,11 €$ & $43.961,89 €$ & $31.019,67 €$ \\
\hline Discapacidad física 3 (DF3) & $95.312,88 €$ & $40.425,11 €$ & $81.565,32 €$ & $38.808,84 €$ \\
\hline \multicolumn{5}{|c|}{ INTELECTUAL } \\
\hline $\begin{array}{l}\text { Discapacidad intelectual } 1 \\
\text { (DI1) }\end{array}$ & $27.441,01 €$ & $10.011,11 €$ & $16.128,29 €$ & $9.687,35 €$ \\
\hline $\begin{array}{l}\text { Discapacidad intelectual } 2 \\
\text { (DI2) }\end{array}$ & $40.107,96 €$ & $17.894,55 €$ & $32.193,06 €$ & $19.250,84 €$ \\
\hline $\begin{array}{l}\text { Discapacidad intelectual } 3 \\
\text { (DI3) }\end{array}$ & $79.063,44 €$ & $24.175,67 €$ & $70.238,02 €$ & $27.481,54 €$ \\
\hline \multicolumn{5}{|c|}{ VISUAL } \\
\hline Resto visual (DV1) & $26.423,98 €$ & $8.994,08 €$ & $17.156,96 €$ & $10.716,02 €$ \\
\hline Ceguera total (DV2) & $34.797,16 €$ & $12.583,75 €$ & $24.470,35 €$ & $11.528,13 €$ \\
\hline \multicolumn{5}{|c|}{ AUDITIVA } \\
\hline Lengua oral (DA1) & $24.870,02 €$ & $7.440,12 €$ & $20.774,98 €$ & $14.334,04 €$ \\
\hline Lengua de signos (DA2) & $24.303,69 €$ & $6.873,79 €$ & $20.124,65 €$ & $13.683,71 €$ \\
\hline \multicolumn{5}{|c|}{ TRASTORNO MENTAL } \\
\hline Trastorno mental 1 (TM1) & $26.090,40 €$ & $8.660,50 €$ & $16.350,91 €$ & $9.909,97 €$ \\
\hline Trastorno mental 2 (TM2) & $38.514,42 €$ & $16.301,01 €$ & $31.084,93 €$ & $18.142,71 €$ \\
\hline Trastorno mental 3 (TM3) & $83.557,94 €$ & $28.670,17 €$ & $68.135,94 €$ & $25.379,46 €$ \\
\hline
\end{tabular}

Fuente: elaboración propia.

La información recogida en la tabla 7 aporta luz sobre el agravio comparativo económico anual medio soportado por cada perfil de discapacidad considerado y pone de manifiesto la importante dispersión de los datos y la dependencia con respecto al perfil de discapacidad y al grupo de edad considerado. También distingue entre el agravio comparativo económico total y el computado en base a los costes directos.

Desde la perspectiva del agravio comparativo contemplando los costes directos, los valores medios anuales para el grupo de edad de 6 a 65 años, basculan entre los casi $7.500 €$ (DA1) y los $40.500 €(D F 3)$.

Se constata también que el envejecimiento tiende a incrementar los valores asociados al agravio comparativo económico si se consideran solamente los costes de carácter directo. En cambio, el montante de costes indirectos tiende a disminuir con la edad de la persona con discapacidad (al reducirse el tiempo de esperanza de vida computable). 


\section{7 . Propuestas de tarifación}

Con la información derivada del agravio comparativo económico se han realizado propuestas de tarifación en la oferta de servicios públicos realizada desde el consistorio de Barcelona.

La tabla siguiente refleja la prevalencia de los distintos perfiles de discapacidad contemplados en el análisis, según la franja de edad, en la ciudad de Barcelona.

\begin{tabular}{|c|c|c|}
\hline PERFIL DE DISCAPACIDAD & $\begin{array}{l}\text { PORCENTAJE POBLACIÓN } \\
\text { (6 a } 64 \text { años) }\end{array}$ & $\begin{array}{c}\text { PORCENTAJE POBLACIÓN } \\
\text { (65 años o más) }\end{array}$ \\
\hline \multicolumn{3}{|c|}{ FÍSICA } \\
\hline Discapacidad física (DF1) & $31,78 \%$ & $38,23 \%$ \\
\hline Discapacidad física (DF2) & $10,60 \%$ & $17,42 \%$ \\
\hline Discapacidad física (DF3) & $5,46 \%$ & $14,15 \%$ \\
\hline \multicolumn{3}{|c|}{ INTELECTUAL } \\
\hline Discapacidad intelectual (DI1) & $6,73 \%$ & $0,19 \%$ \\
\hline Discapacidad intelectual (DI2) & $3,33 \%$ & $0,33 \%$ \\
\hline Discapacidad intelectual (DI3) & $3,85 \%$ & $0,37 \%$ \\
\hline \multicolumn{3}{|c|}{ VISUAL } \\
\hline Resto visual (DV1) & $2,93 \%$ & $3,76 \%$ \\
\hline Ceguera total (DV2) & $2,51 \%$ & $4,88 \%$ \\
\hline \multicolumn{3}{|c|}{ AUDITIVA } \\
\hline Lengua oral (DA1) & $4,59 \%$ & $5,69 \%$ \\
\hline Lengua de signos (DA2) & $0,35 \%$ & $0,43 \%$ \\
\hline \multicolumn{3}{|c|}{ TRASTORNO MENTAL } \\
\hline Trastorno mental 1 (TM1) & $9,35 \%$ & $3,96 \%$ \\
\hline Trastorno mental 2 (TM2) & $15,87 \%$ & $4,56 \%$ \\
\hline Trastorno mental 3 (TM3) & $2,66 \%$ & $6,03 \%$ \\
\hline
\end{tabular}

Fuente: elaboración propia a partir del Censo de Personas con Discapacidad - Barcelona (2016) por grupo de edad.

A partir de la combinación de los datos recogidos en las tablas 7 y 8 , se ha calculado el valor medio del agravio comparativo económico por discapacidad (AED), ponderándose el montante asociado a cada uno de los trece perfiles de discapacidad por su prevalencia según el censo de personas con discapacidad y distinguiendo las dos franjas de edad consideradas. La tabla 9 recoge los valores totales y sobre los costes directos. 


\begin{tabular}{|c|c|c|}
\hline & $\begin{array}{l}\text { AGRAVIO COMPARATIVO } \\
\text { ECONÓMICO (AED) TOTAL }\end{array}$ & $\begin{array}{l}\text { AGRAVIO COMPARATIVO } \\
\text { ECONÓMICO (AED) SOBRE } \\
\text { COSTES DIRECTOS }\end{array}$ \\
\hline 6 a 64 años & $41.203,54 €$ & $17.743,47 €$ \\
\hline 65 años o más & $36.785,46 €$ & $21.111,22 €$ \\
\hline
\end{tabular}

Fuente: elaboración propia.

Tales valores medios ponderados anuales permiten simplificar y ofrecer una idea más clara del impacto del agravio comparativo económico soportado por las personas con discapacidad de la ciudad de Barcelona y, a la vez, proponer algunas soluciones en materia de políticas públicas para ofrecer soluciones adaptadas a cada situación concreta (evitando soluciones homogeneizantes).

La propuesta de tarifación se ha construido en base a la relación existente entre el agravio comparativo económico asignado a cada perfil de discapacidad y el agravio comparativo medio computado (AED) para cada franja de edad, construyéndose una tabla de referencia (tabla 10) que ha permitido identificar los valores extremos del agravio comparativo, como el del grupo DF3 del grupo de edad de 6 a 64 años (227\% más elevado que el valor medio del agravio comparativo en esta franja de edad) o el del perfil TM3, un 161\% más elevado.

Según la propuesta realizada, los criterios de tarifación deberían separarse de bonificaciones y/o exenciones homogéneas para todo el colectivo de personas con discapacidad y adaptar la gradación de ayudas al agravio comparativo económico realmente soportado.

\begin{tabular}{|c|c|c|}
\hline PERFIL DE DISCAPACIDAD & $\begin{array}{c}\text { DIFERENCIA DEL AGRAVIO } \\
\text { COMPARATIVO ECONÓMICO } \\
\text { RESPECTO AL ÍNDICE AED } \\
(6 \text { a } 64 \text { años) }\end{array}$ & \begin{tabular}{|} 
DIFERENCIA DEL AGRAVIO COMPARATIVO \\
ECONÓMICO \\
RESPECTO AL ÍNDICE AED \\
(65 años o más) \\
\end{tabular} \\
\hline \multicolumn{3}{|c|}{ FísICA } \\
\hline Discapacidad física 1 (DF1) & $86,46 \%$ & $67,41 \%$ \\
\hline Discapacidad física 2 (DF2) & $178,51 \%$ & $146,93 \%$ \\
\hline Discapacidad física 3 (DF3) & $227,83 \%$ & $183,83 \%$ \\
\hline \multicolumn{3}{|c|}{ INTELECTUAL } \\
\hline Discapacidad intelectual 1 (DI1) & $56,42 \%$ & $45,89 \%$ \\
\hline Discapacidad intelectual 2 (DI2) & $100,85 \%$ & $91,19 \%$ \\
\hline Discapacidad intelectual 3 (DI3) & $136,25 \%$ & $130,18 \%$ \\
\hline \multicolumn{3}{|c|}{ VISUAL } \\
\hline Resto visual (DV1) & $50,69 \%$ & $50,76 \%$ \\
\hline Ceguera total (DV2) & $70,92 \%$ & $54,61 \%$ \\
\hline
\end{tabular}

Interpretación de los colores:

Del 0,00 al 49,99\% del índice medio ponderado Del 100,00 al 199,99\% del índice medio ponderado
Del 50,00 al 99,99\% del índice medio ponderado

Más del $200 \%$ del índice medio ponderado 


\begin{tabular}{|c|c|c|}
\hline PERFIL DE DISCAPACIDAD & $\begin{array}{c}\text { DIFERENCIA DEL AGRAVIO } \\
\text { COMPARATIVO ECONÓMICO } \\
\text { RESPECTO AL ÍNDICE AED } \\
\text { (6 a } 64 \text { años) }\end{array}$ & $\begin{array}{c}\text { DIFERENCIA DEL AGRAVIO COMPARATIVO } \\
\text { ECONÓMICO } \\
\text { RESPECTO AL ÍNDICE AED } \\
\text { (65 años o más) }\end{array}$ \\
\hline \multicolumn{3}{|c|}{ AUDITIVA } \\
\hline Lengua oral (DA1) & $41,93 \%$ & $67,90 \%$ \\
\hline Lengua de signos (DA2) & $38,74 \%$ & $64,82 \%$ \\
\hline \multicolumn{3}{|c|}{ TRASTORNO MENTAL } \\
\hline Trastorno mental 1 (TM1) & $48,81 \%$ & $46,94 \%$ \\
\hline Trastorno mental 2 (TM2) & $91,87 \%$ & $85,94 \%$ \\
\hline Trastorno mental 3 (TM3) & $161,58 \%$ & $120,22 \%$ \\
\hline
\end{tabular}

Interpretación de los colores:

Del 0,00 al 49,99\% del índice medio ponderado Del 100,00 al $199,99 \%$ del índice medio ponderado

\section{Principales conclusiones}

En el proceso de cálculo del agravio comparativo económico de las personas con discapacidad, se han comparado los costes y los ingresos para obtener la cuantificación asociada al valor del agravio comparativo asociado a cada perfil de discapacidad.

Los resultados obtenidos permiten poner de relieve un conjunto de evidencias en el marco de análisis del agravio comparativo económico derivado de la situación de discapacidad:

1. Cabe constatar la posibilidad de identificar de manera precisa el agravio comparativo económico medio asociado a cada perfil de discapacidad cuantificándose en base a las respectivas necesidades de apoyo constatadas y en función de la naturaleza del gasto (tabla 8).

2. Por primera vez se tiene en cuenta el grupo de personas mayores de 65 años y sus particularidades y necesidades específicas a la hora de aproximar el valor medio del agravio comparativo económico soportado por las personas con discapacidad y sus núcleos de convivencia (tabla 8) y se constata su efecto diferencial.

3. Se pone en evidencia que el agravio comparativo económico en base a los costes directos para el colectivo de personas de 6 a 64 años es menor que el de las personas de 65 años o más. Además, el efecto del coste de oportunidad en términos de salarios tiene un mayor impacto en el colectivo en edad de trabajar (tablas 2 y 4); es decir, los costes indirectos son tanto más importantes cuanto más joven sea la persona considerada.

4. Se constata el impacto determinante del grado de discapacidad sobre los costes de oportunidad que soporta el cuidador principal. 
5. Deberían actualizarse periódicamente tanto los conceptos como los importes asociados a los costes imputados y a las bonificaciones estimadas.

6. Sería necesario incorporar tanto el grado de discapacidad como el agravio comparativo económico soportado a la hora de definir políticas públicas de tarifación.

7. Se debería avanzar en términos de tarifación y políticas públicas, modulando sus consecuencias sobre la renta que necesita cada colectivo de acuerdo con sus necesidades de apoyo y edad (tabla 10).

\section{Recomendaciones}

Al amparo de las principales conclusiones derivadas del presente estudio, así como a la luz de la información extrapolada del análisis de diferentes bases de datos, resulta procedente realizar una serie de recomendaciones de cara al desarrollo de futuras líneas de investigación.

- Cabe adaptar los perfiles de discapacidad objeto de análisis en base a los cambios observados recientemente.

- Convendría realizar una mayor segregación de los grupos de edad objeto de análisis.

- Es obligado articular actuaciones en clave de género que contemplen el predominio de la mujer en el papel de cuidadora principal de la persona con discapacidad.

- Deberían estructurarse las políticas públicas en una estrategia transversal de apoyo a entidades que, otorgando recursos y evitando duplicidades, ayuden a superar los agravios comparativos de diferente tipología a los que hacen frente las personas con discapacidad y su entorno.

- Cabe introducir mejoras en los sistemas de información existentes para que faciliten datos fiables, integrados e integrales sobre la población con discapacidad y paliar la nula integración actual.

- Se deberían articular de manera eficiente y eficaz los recursos disponibles, evitando políticas de homogeneización de ayudas destinadas a un colectivo claramente heterogéneo.

- Resultaría interesante comparar el agravio comparativo económico del colectivo con discapacidad que reside en un contexto institucionalizado con el enmarcado en un contexto de vida independiente.

- Cabe analizar la pluridiscapacidad (en una única persona o cuando conviven dos o más personas con discapacidad).

- Se pone de relieve la necesidad de articular políticas públicas que compensen el agravio comparativo económico estimado y evitar así situaciones de riesgo de exclusión social.

- Debería incluirse el perfil de discapacidad como variable en políticas de tarifación social, de modo que los tributos, tasas y precios públicos de acceso a bienes y servicios tuviesen en cuenta el agravio comparativo económico soportado según la tipología y el grado de discapacidad de cada usuario. 


\section{Referencias bibliográficas}

Antares Consulting (2006). El greuge comparatiu econòmic de les persones amb discapacitat de la ciutat de Barcelona. El sobreesforç econòmic que origina la discapacitat. Instituto Municipal de Personas con Discapacidad, Ayuntamiento de Barcelona. https://ajuntament.barcelona.cat/dretssocials/sites/default/files/arxiusdocuments/Estudi\%20greuge\%20comparatiu\%20economic\%20de\%20les\%20persones\%20amb\%20discpacitat.pdf.

Antón J. I. et al. (2016). An analysis of the cost of disability across Europe using the standard of living approach. Journal of the Spanish Economic Association, SERIEs 7, pp. 281-306.

Antón J. I. y Braña, F. J. (2011). Pobreza, discapacidad y dependencia en España. Papeles de Economía Española, 129, pp. 14-26.

Área de Derechos Sociales, Ayuntamiento de Barcelona (2017). Persones amb reconeixement legal de discapacitat a la ciutat de Barcelona 2016. Característiques i distribució territorial. https://media-edg.barcelona.cat/ wp-content/uploads/2017/12/20130623/Informe-Persones-amb-Discapacitat-2016.pdf.

Berthoud, R. (1991). Meeting the costs of disability. En G. Dalley (Ed.), Disability and Social Policy. Policy Studies Institute.

Cullinan, J. et al. (2008). Estimating the economic cost of disability in Ireland. Working Paper 230. Economic and Social Research Institute.

Cullinan, J. et al. (2013). The welfare implications of disability for older people in Ireland. European Journal Health Economics, 14(2), pp. 171-183.

Dobson, B. et al. (2001). The impact of childhood disability on family life. Joseph Rowntree Foundation.

Feaps, Confederación Española de Asociaciones a favor de las Personas con Discapacidad Intelectual (2009). Estudio del sobreesfuerzo económico que la discapacidad intelectual ocasiona en la familia en España. Feaps. https://1library.co/document/zx9113vz-estudio-sobreesfuerzo-economico-discapacidad-intelectual-ocasiona-familia-espana.html.

Hill, K. et al. (2015). Disability and minimum living standards: The additional costs of living for people who are sight impaired and people who are deaf. Centre for Research in Social Policy, Loughborough University. https:// repository.Iboro.ac.uk/articles/Disability_and_minimum_living_standards_the_additional_costs_of_living_for_ people_who_are_sight_impaired_and_people_who_are_deaf/9471404/files/17095817.pdf.

Hirsch, D. y Hill, K. (2016). The additional cost of disability: a new measure and its application to sensory impairment. Disability \& Society, 31(7), pp. 897-913.

Imserso, Instituto de Mayores y Servicios Sociales (2004). Libro Blanco: atención a las personas en situación de dependencia en España. Secretaría de Estado de Servicios Sociales, Familias y Discapacidad. Ministerio de Trabajo y Asuntos Sociales. Imserso. https://www.imserso.es/InterPresent2/groups/imserso/documents/binario/libroblanco.pdf.

Indecon, International Economic Consultants (2004). Cost of Disability Research Project Report. Submitted to the National Disability Authority. http://nda.ie/File-upload/Indecon-Report-on-the-Cost-of-Disability.pdf. 
Instituto Nacional de Estadística (2008a). Encuesta de Discapacidad, Autonomía personal y situaciones de Dependencia (EDAD). https://www.ine.es/dyngs/INEbase/es/operacion.htm?c=Estadistica_C\&cid=1254736176782\& menu=resultados\&idp $=1254735573175$.

Instituto Nacional de Estadística (2008b). Encuesta de condiciones de vida 2007. https://www.ine.es/dynt3/inebase/index.htm?type=pcaxis\&path=/t25/p453/a2007/\&file=pcaxis.

Jiménez-Lara, A. y Huete-García, A. (2011). Estudio sobre el agravio comparativo económico que origina la discapacidad. Ministerio de Sanidad, Política Social e Igualdad. Universidad Carlos III de Madrid. https://consaludmental.org/publicaciones/Estudioagravioeconomicodiscapacidad.pdf.

Kuklys, W. (2004). A Monetary Approach to Capability Measurement of the Disabled - Evidence from the UK. Papers on Strategic Interaction, 2004-08. Max Planck Institute of Economics. Strategic Interaction Group.

Martin, J. y White, A. (1988). The financial circumstances of disabled adults living in private households. Report 2. Great Britain Office of Population Censuses Surveys. HMSO.

Matthews, A. y Truscott, P. (1990). Disability, household income and expenditure: A follow-up survey of disabled adults in the family expenditure survey. Research Reports 2. Department of Social Security. HMSO.

Mitra, S. et al. (2017). Extra costs of living with a disability: A review and agenda for research. Disability and Health Journal, 10(4), pp. 475-484.

Morciano, M. y Hancock, R. (2015). Disability costs and equivalence scales in the older population in Great Britain. The Review of Income and Wealth, 61(3), pp. 494-514.

Saunders, P. (2007). The costs of disability and the incidence of poverty. Australian Journal of Social Issues. 42(4), pp. 461-480.

Smith, N. et al. (2004). Disabled people's costs of líving: More than you would think. Joseph Rowntree Foundation.

Tibble, M. (2005). Review of existing research on the extra costs of disability. Paper Series 21. Department of Work and Pensions.

van den Berg, B. et al. (2004). Economic valuation of informal care. An overview of methods and applications. European Journal of Health Economics, 5, pp. 36-45.

Wilkinson-Meyers, L. et al. (2010). Estimating the additional cost of disability: Beyond budget standards. Social Science and Medicine, 71, pp. 1882-1889.

Wilkinson-Meyers L., et al. (2015). To live an ordinary life: resource needs and additional costs for people with a physical impairment. Disability \& Society, 30(7), pp. 976-990.

Zaidi, A. y Burchart, T. (2005). Comparing incomes when needs differ for the extra costs of disability in the UK. Review of Income and Wealth, 51(1), pp. 89-114. 